\title{
P04-5-7 Poster session
}

\section{Role of $\mathrm{HONO}$ in the relationship between $\mathrm{NO}_{2}$ and mild asthma attacks}

\section{Masayuki Ohyama ${ }^{1}$, Takae Nakajima$^{1}$, Chika Minejima $^{2}$, Kenichi Azuma $^{3}$, Yasuyuki Itano ${ }^{4}$, Norimichi Takenaka ${ }^{5}$}

${ }^{I}$ Department of Environmental Health, Osaka Institute of Public Health, Japan, ${ }^{2}$ International Christian University, Japan, ${ }^{3}$ Kindai University, Japan, ${ }^{4}$ Osaka City Research Center of Environmental Science, Japan, ${ }^{5}$ Osaka Prefecture University, Japan

Background: The relationship between $\mathrm{NO}_{2}$ and asthma has been investigated; however, the WHO (2005) has reported that it is unclear to what extent the health effects observed in epidemiological studies are attributable to $\mathrm{NO}_{2}$ itself or to the other primary and secondary combustion-related products with which it is typically correlated.

Objectives: To obtain a reasonable hypothesis for the contradictions concerning relationships between $\mathrm{NO}_{2}$ and asthma symptoms by this descriptive epidemiological study.

Methods: We examined the relationships between indoor and monitoring station $\mathrm{NO}_{2}$, indoor HONO (primary combustion-related products, decomposed by sunlight, generated from $\mathrm{NO}_{2}$ after sunset), and self-reported asthma symptoms from 2010 through 2012 for five childhood asthma patients per year in Kishiwada, Japan, from autumn to winter. We used a simple Mann-Whitney $U$-test and $r^{2}$ to examine relationships between the various data for the entire study period and for the first half of the study period.

Results: Monitoring station $\mathrm{NO}_{2}$ was significantly associated with self-reported mild asthma attacks in the first half of the study period in 2012, 2011-2012, and 2010-2012 according to $U$-tests, but not over the entire study period. Moreover, indoor $\mathrm{NO}_{2}$, which was usually higher in concentration than monitoring station $\mathrm{NO}_{2}$, was not significantly associated with self-reported mild asthma attacks in both study periods or any year. Indoor HONO was significantly associated with selfreported mild asthma attacks in the first half of the study period in 2010, 2010-2011, and 2011-2012. Indoor HONO was correlated with monitoring station $\mathrm{NO}_{2}$ in $2011\left(r^{2}=0.97\right)$ and $2012\left(r^{2}=0.55\right)$, as well as with indoor NO in $2010\left(r^{2}=\right.$ $0.75)$ in the first half of the study period.

Conclusion: We hypothesize that HONO is a more important nitrogen oxide in mild asthma attacks than $\mathrm{NO}_{2}$ and that the significant association between monitoring station $\mathrm{NO}_{2}$ and mild asthma attacks depends on $\mathrm{HONO}$ generated from outdoor $\mathrm{NO}_{2}$ at night. 